Ensayo

\title{
Formación editorial: la mediación de textos didácticos a través de El portafolio del escritor
}

\section{Editorial training: the mediation of didactic texts through the writer's portfolio}

Jessie Jonathan Alvarez Marroquín Universidad de San Carlos de Guatemala jessiealvarezm@profesor.usac.edu.gt

Norma Liliana Chamalé Patzán Universidad de San Carlos de Guatemala normitachamale@gmail.com

Edvin Antonio Méndez Vásquez Universidad de San Carlos de Guatemala edvinanthl1@hotmail.com

Andrea Regina Rodriguez Rivas Universidad de San Carlos de Guatemala regina.editorial@gmail.com

Maestría en Edición Editorial Universidad de San Carlos de Guatemala

\section{Referencia del ensayo}

Alvarez, J., Chamalé, N., Méndez, E. y Rodriguez, A. (2021). Formación editorial: la mediación de textos didácticos a través del portafolio del escritor. Revista Guatemalteca de Cultura. 1(2) 28-35, DOI 10.46954/revistaguatecultura.v1i2.12 


\section{Resumen}

Cada vez, el segmento de textos didácticos se fortalece más en el mercado editorial, por lo que los procesos de formación de editores deben tomar en cuenta sus particularidades. Uno de estos aspectos es la mediación pedagógica, que aborda tanto lo visual como lo textual. Para analizar cómo se han realizado procesos de mediación de contenidos, se estudia el folleto 5, «El ensayo», de la serie El portafolio de escritor, publicado en 2018 por la Dirección General de Evaluación e Investigación Educativa (Digeduca), la dependencia del Ministerio de Educación de Guatemala (Mineduc) que se encarga de crear, mediar y distribuir contenido relacionado con la evaluación de estudiantes y docentes del sistema escolar nacional. El objetivo de El portafolio del escritor es darles herramientas a los docentes para que ayuden a los estudiantes a mejorar sus habilidades de lectura, por lo que la mediación pedagógica es muy importante. Un análisis de las estrategias de mediación permite comprender cómo se acerca el contenido del ensayo a los docentes para que ellos, a su vez, se lo presenten a los estudiantes. Es importante que los editores en formación aprendan cuestiones relacionadas con la mediación pedagógica, por ejemplo. Para esto, ejercicios como el análisis en el proceso de edición benefician el aprendizaje, pues ayuda a sistematizar la experiencia de otros editores, y les sirve como una mirada crítica a los futuros editores.

Palabras clave: textos didácticos, mediación pedagógica, formación editorial, industria editorial

\section{Abstract}

Every time, the didactic texts segment is getting stronger in the publishing market, so the editors' training processes must take into account their particularities. One of these aspects is pedagogical mediation, which addresses both the visual and the textual. To analyze how content mediation processes have been carried out, brochure 5, «El ensayo», of the series El portafolio del escritor, published in 2018 by the Dirección General de Evaluación e Investigación Educativa (Digeduca), the dependency of the Ministry of Education of Guatemala (Mineduc) that is in charge of creating, mediating and distributing content related to the evaluation of students and teachers of the national school system. The objective of El portafolio 
del escritor is to give teachers tools to help their students improve their reading skills, so pedagogical mediation is very important. An analysis of the mediation strategies allows us to understand how the content of the essay is approached to the teachers so that they, in turn, present it to their students. It is important that editors-in-training learn about issues related to pedagogical mediation, for example. For this, exercises such as analysis in the editing process benefit learning, as it helps to systematize the experience of other editors, which serves as a critical look at future editors.

Keywords: didactic texts, pedagogical mediation, editorial training, publishing industry

\section{Contenido}

\section{Formación editorial}

\section{La mediación de textos didácticos a través de El portafolio del escritor}

En el imaginario colectivo, ronda la idea de que una tarde perfecta puede incluir lluvia, café y, por supuesto, un buen libro. Sin embargo, como suele suceder con las imágenes estereotípicas, idílicas y descontextualizadas que circulan en las redes sociales, los usuarios comparten memes que ridiculizan esa posición hegemónica y muestran fotografías de catástrofes causadas por la lluvia en las que también aparece algún café de baja calidad y, claro, un «mal» libro. Esto obliga a preguntarse qué es un mal libro: ¿acaso uno con un contenido banal o uno con errores de ortografía? ¿Acaso, alguno cuya información sea errónea o innecesaria?
Estas últimas son preguntas necesarias para las personas que se dedican a la labor editorial, ya que de sus respuestas dependerá la línea que acojan en su producción, lo cual también implica que un editor necesita tener procesos de aprendizaje desde estas perspectivas. El área de estudios de la edición editorial debe contemplar el conocimiento del mercado editorial y los componentes de esta industria, que incluyen desde el proceso de escritura hasta la impresión o publicación en el soporte respectivo, pasando por la mediación de los contenidos.

Si se sigue el esquema de la edición propuesto por Michael Bhaskar, quien propone que el proceso editorial está formado por cuatro dimensiones: filtrado, enmarcado, amplificación y modelo, se comprende que cada etapa de la edición de un texto es fundamental para que este llegue con la mejor calidad posible al lector. También es necesario considerar que el mercado editorial está formado por varios segmentos, a saber: literatura, textos 
didácticos, textos religiosos y textos técnicos. Por lo tanto, una persona que se prepara para trabajar en el mundo de la edición debe tener un acercamiento a todas las dimensiones en todos los segmentos del libro, lo que le ayudará a comprender mejor el detallado engranaje del mundo editorial.

En ese sentido, se plantea una pregunta importante al estudiar edición: ¿Por qué es indispensable el trabajo editorial en la publicación de textos escolares? En otras palabras, ¿por qué los estudiantes de edición editorial necesitan aprender acerca de la mediación pedagógica?, ¿Qué habilidades deben desarrollar los futuros editores para hacer el mejor trabajo posible? Estas son algunas inquietudes que interesa responder a través de este ensayo.

Para analizar esta perspectiva, se estudió el proceso de edición de El portafolio del escritor, un contenido publicado en 2018 por la Dirección General de Evaluación e Investigación Educativa (Digeduca), la dependencia del Ministerio de Educación de Guatemala (Mineduc) que se encarga de crear, mediar y distribuir contenido relacionado con la evaluación de estudiantes y docentes del sistema escolar nacional. El portafolio del escritor es una serie de folletos dirigidos a docentes de Comunicación y Lenguaje de tercero básico y las carreras de cuarto diversificado con el objetivo de consolidar «las habilidades de comunicación escrita (leer y escribir) [pues] el docente tiene el reto de formar lectores que sean capaces de utilizar la lengua escrita tanto para acceder a nuevos conocimientos y aprender, como para expresarse» (Digeduca: 1).
En consonancia de este objetivo, el portafolio del escritor está formado por siete folletos que definen, explican, ejemplifican, modelan y dan orientaciones pedagógicas (planificación, enseñanza y evaluación) de varios tipos textuales, entre los que se encuentran la carta, el correo electrónico, el resumen, la noticia, el ensayo, el formulario y el instructivo. Además, cuenta con un proyecto hermano que tiene el mismo objetivo, pero con textos literarios: El portafolio del escritor creativo. Para efectos de esta investigación se revisó El portafolio del escritor, que puede descargar gratuitamente de la página de Digeduca, y se decidió enfocarse en el folleto 5 , «El ensayo».

Tal como indica Bhaskar (2014), «cuando los editores eran guardianes, seleccionaban. Ahora que todo mundo publica, aún pueden crear un público mediante un hábil cuidado del contenido» (p. 230), el trabajo del editor ya no es solo elegir qué se publica, sino mediarlo de tal forma que su público objetivo quiera leerlo. Por esa razón, es interesante descubrir qué mecanismos de mediación pedagógica y didáctica utilizó el editor de este material. El editor, por lo tanto, necesita comprender con profundidad los objetivos de la publicación, pues a partir de estas líneas habrá de cuidar que todo el contenido se esté desarrollando de forma adecuada. Esta es una de las primeras habilidades que un editor de contenido didáctico necesita desarrollar: comprender las relaciones entre los objetivos del material y la forma en que se está abordando el contenido, así como la forma en que estos se presentan, ya sea a través de la diagramación como del manejo del texto en sí. 
En el segmento de los textos didácticos, conocer los objetivos es imprescindible, pues su público objetivo, directo o indirecto, son miles de estudiantes que necesitan aprender a leer para comprender mejor el mundo e interactuar con el a través de los textos; sobre todo, en una sociedad como la guatemalteca, donde se presentan datos como los siguientes:

Tabla 1: Indicadores relacionados con la lectura y la industria editorial

\begin{tabular}{|c|c|c|c|c|c|c|c|}
\hline \multirow{4}{*}{ País } & \multirow{3}{*}{\begin{tabular}{|c|}
$\begin{array}{c}\text { Población } \\
\text { total }\end{array}$ \\
$\begin{array}{c}\text { En } \\
\text { millones }\end{array}$
\end{tabular}} & \multirow{3}{*}{$\begin{array}{c}\text { Porcentajes de } \\
\text { la población de } \\
15 \text { años y más } \\
\text { que sabe leer y } \\
\text { escribir }\end{array}$} & \multirow{3}{*}{$\begin{array}{c}\text { Tasa } \\
\text { neta de } \\
\text { matrícula } \\
\text { nivel } \\
\text { secundario }\end{array}$} & \multirow{4}{*}{$\begin{array}{c}\text { El país } \\
\text { cuenta } \\
\text { con una } \\
\text { ley del } \\
\text { libro y la } \\
\text { lectura }\end{array}$} & \multicolumn{3}{|c|}{ Producción editorial } \\
\hline & & & & & \multirow{2}{*}{$\begin{array}{c}\text { Número } \\
\text { de } \\
\text { títulos } \\
\text { con } \\
\text { ISBN }\end{array}$} & \multicolumn{2}{|c|}{$\begin{array}{c}\text { Comercio internacional de } \\
\text { libros (en millones de US } \\
\text { Dólares) }\end{array}$} \\
\hline & & & & & & Exportaciones & Importaciones \\
\hline & 2015 & \multicolumn{2}{|c|}{2013} & & \multicolumn{3}{|c|}{ Suma de 2011 a 2015* } \\
\hline Costa Rica & 4.8 & 97.6 & 74.6 & $\mathrm{Si}$ & 8,246 & 41 & 170.4 \\
\hline El salvador & 6.3 & 88.2 & 63.3 & $\mathrm{Si}$ & 3,133 & 25.8 & 108.1 \\
\hline Guatemala & 16.4 & 84.3 & 37.4 & $\mathrm{Si}$ & 5,555 & 14.1 & 206.5 \\
\hline Honduras & 8.1 & 85.3 & 34.3 & $\mathrm{Si}$ & 2,255 & 1.2 & 90.7 \\
\hline Nicaragua & 6.1 & 97 & s.d. & No & 1,633 & 4.1 & 82.5 \\
\hline Panamá & 3.9 & 97.9 & 58.7 & No & 8,213 & 38.2 & 208.5 \\
\hline Centroamérica & 45.6 & 97.7 & & & 29,035 & 124.4 & 866.7 \\
\hline
\end{tabular}

Fuente: Icefi con base en CERLALC/Unesco. El libro en cifras. Boletín estadístico del libro en Iberoamérica, ediciones 1, 2, 3, 5, 7, y 9. Los datos sobre población que sabe leer y escribir y la tasa neta de matrícula secundaria provienen de estadísticas oficiales.

Es decir, el país cuenta con una ley de libro $\mathrm{y}$ es el tercero en Centroamérica en cuanto a la producción de libros con International Standard Book Number (ISBN), pero aun así, para 2013, 84.3\% de los jóvenes de más de 15 años no sabían leer ni escribir. En ese sentido, el editor de textos didácticos tiene una labor fundamental, pues debe acercar el texto a los docentes y a los alumnos para que la calidad de la educación mejore, por lo menos para los jóvenes que participan en un modelo educativo, ya sea formal o informal.
Así, se llega a otro elemento que un editor en formación necesita conocer: el contexto de su público objetivo. Antes de editar un texto dirigido a docentes, debe preguntarse cuál es el nivel de comprensión lectora, no solo de los alumnos, sino de los profesores mismos, ya que esto determinará su estilo y el nivel del lenguaje del texto. Esta es una diferencia que el editor debe saber que existe según el segmento al que se dedique; un editor de literatura, por ejemplo, sabe que las novelas o los libros de cuentos o poemas que edita 
llegarán a personas que los están buscando, en cambio - en su caso- es el texto el que debe ir en busca de sus lectores y adecuarse a los múltiples factores que puedan intervenir.

Este factor también incide en la elección de la diagramación. Tal como se en el folleto del ensayo, y en toda la colección El portafolio del escritor, las ilustraciones son a un solo color, pues el costo de la impresión de los miles de folletos para docentes de todo el país es un recurso que debe tomarse en cuenta; de hecho, todos los folletos están impresos a dos tintas. Este es un reto para el diseñador, quien debe lograr que el material sea llamativo para los docentes y, al mismo tiempo, debe usar pocas tonalidades. Por lo tanto, es una cuestión que el editor debe saber ver.

Esas mismas consideraciones del contexto del público objetivo, se toman también en el manejo del lenguaje. El folleto analizado está escrito con un lenguaje llano en un registro formal y objetivo, por lo que las oraciones son de mediana extensión y hay suficientes marcadores del discurso que faciliten la lectura y comprensión del texto. Asimismo, se evita un léxico muy especializado y se favorece el uso de textos discontinuos, como listas y esquemas, tal como puede verse en esta página:
Figura No. 1 Tipos de ensayos

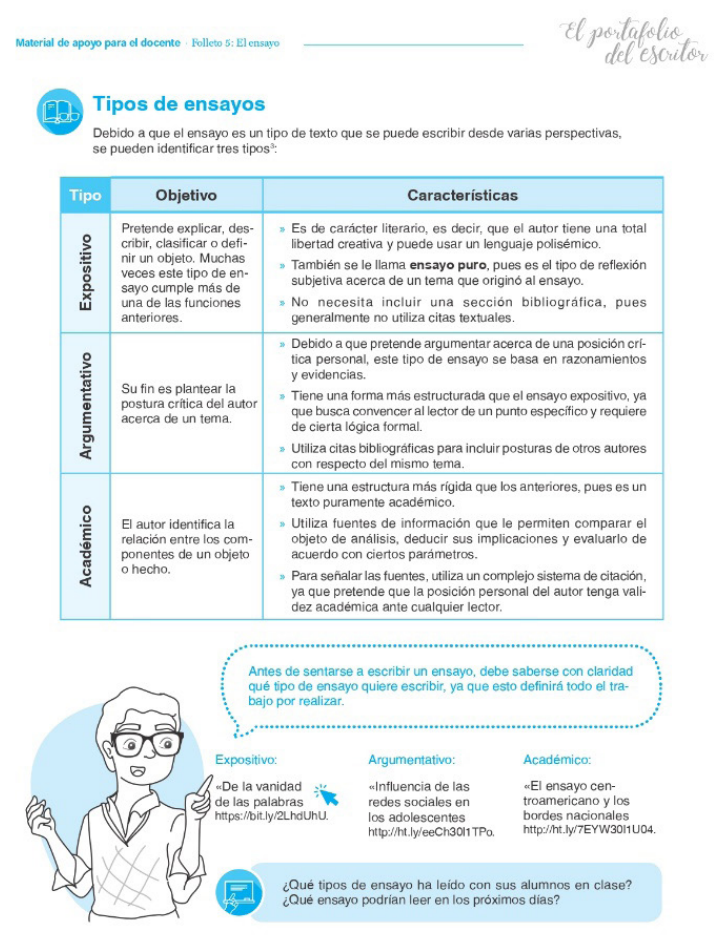

Fuente: Ministerio de Educación de Guatemala. Dirección General de Evaluación e Investigación Educativa. (2018). El portafolio del escritor. Nivel de Educación MediaComunicación y Lenguaje Material de apoyo para el docente. Página 3.

En lugar de escribir largos textos descriptivos que definan los tipos de ensayo, se optó por una tabla que organiza la información en filas y columnas para que los docentes puedan localizar con mayor facilidad los temas de su interés. También se observa que, por cuestiones de economía, en lugar de ejemplos de ensayos se colocaron enlaces para que los docentes los lean. Llama la atención que se hayan colocado los sitios acortados en lugar de códigos qr; probablemente por la dificultad que algunos docentes puedan tener en el uso de la tecnología. 
Justamente, en esto consiste la mediación pedagógica: tomar en cuenta todos los aspectos que influyan en la recepción y percepción del contenido para facilitar su comprensión a través de distintos elementos, tanto gráficos, como el color, las ilustraciones, la tipografía y la diagramación, como textuales, tales como el estilo, el léxico y la organización de las ideas. Como se sabe, esta es una técnica que se aprende, no un talento natural, por lo que necesita estudiarse para una mejor edición.

La mediación de textos pedagógicos se convierte, entonces, en un área indispensable en la formación de futuros editores, quienes se podrán desempeñar en este segmento, que es uno de los más importantes de la industria cultural, que es nueve millones de dólares anualmente. De acuerdo con datos del Instituto Centroamericano de Estudios Fiscales (Icefi), entre 2011 y 2015, Guatemala importó 206.5 millones de dólares en libros, pero solamente exportó 14.1 millones en la misma moneda.
En otras palabras, la industria editorial es un mercado pujante que necesita editores formados para trabajar en diversos segmentos del mercado y que tengan la capacidad de mediar el contenido de acuerdo con las especificidades de los diversos públicos. Asimismo, es un imperativo que los editores en formación aprendan cuestiones relacionadas con la mediación pedagógica, por ejemplo. Para esto, ejercicios como el análisis en el proceso de edición benefician el aprendizaje, ya que ayudan a sistematizar la experiencia de otros editores, que les sirve como una mirada crítica a los futuros editores.

Esto, sin lugar a dudas, ayudará a que cada vez haya más lectores dispuestos a tomar un libro para acompañar una tarde de lluvia en lugar de solo mofarse de las aventuras de la ficción o la comprensión del mundo que pueden permitirse a través del viaje de la lectura. 


\section{Referencias bibliográficas}

Bhaskar, M. (2014). La máquina de contenido. México: Fondo de Cultura Económica.

CERLAC (2012) El libro en cifras. Boletín estadísticos del libro en Iberoamérica, ediciones 1, 2, 3, 5, 7 y 9 Recuperado de https://icefi. org/sites/default/files/cuadros_observatorio_fiscal_libros_0.pdf

Digeduca. (2018). El ensayo. En El portafolio del escritor. (pág. 12). Guatemala: Ministerio de Educación.

\section{¿Sobre los autores}

Equipo de investigadores de la Maestría en Edición Editorial de la Universidad de San Carlos de Guatemala

\section{Copyright (c) Jessie Jonathan Alvarez Marroquín y colaboradores}

Este texto está protegido por una licencia Creative Commons 4.0.

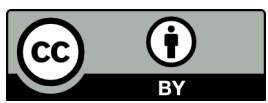

Usted es libre para compartir, copiar y redistribuir el material en cualquier medio o formato y adaptar el documento, remezclar, transformar y crear a partir del material para cualquier propósito, incluso comercialmente, siempre que cumpla la condición de atribución: usted debe reconocer el crédito de una obra de manera adecuada, proporcionar un enlace a la licencia, e indicar si se han realizado cambios. Puede hacerlo en cualquier forma razonable, pero no de forma tal que sugiera que tiene el apoyo del licenciante o lo recibe por el uso que hace. 